\title{
Induction of Hyalurosome by Topical Hyaluronate Fragments Results in Superficial Filling of the Skin Complementary to Hyaluronate Filler Injections
}

\author{
Gürkan Kaya $^{a}$ Aysin Kaya $^{b}$ Jean-Hilaire Saurat ${ }^{b}$ \\ aDepartment of Dermatology, University Hospital of Geneva, Geneva, Switzerland; \\ ${ }^{b}$ Department of Clinical Pharmacology and Toxicology, University of Geneva, Geneva, \\ Switzerland
}

\section{Keywords}

Hyaluronate $\cdot$ Hyalurosome $\cdot$ Dermatoporosis $\cdot$ Epicutaneous filling $\cdot$ Retinoids

\begin{abstract}
Hyaluronate (HA) plays a major role in the process of skin aging. The main use of HA has been for hydration and dermal fillers. Another approach, based on the discovery of the signaling effects of topically applied hyaluronate fragments (HAF), has subsequently been developed. It has been thoroughly demonstrated that topical applications of HAF of a very specific size induce HA filling of the epidermis and the upper dermis. These effects are particularly visible in dermatoporotic patients. Moreover, the combination of HA-based filler injections with topical applications of HAFs/retinoids showed an optimization of the effects of HA. Thus, a new classification of the different effects of HA is proposed here.

(c) 2019 The Author(s)

Published by S. Karger AG, Basel
\end{abstract}

Hyaluronate (HA, hyaluronan, hyaluronic acid) was discovered in 1934 by Meyer and Palmer. It can be found in skin, joints, eyes, and most other organs and tissues. HA is a major component of the extracellular matrix, of which the skin is the main reservoir [1]. It is synthesized at the cell membrane of many cells, in particular in fibroblasts and keratinocytes [2]. It is composed of repeating units of the disaccharide GlcNAc $\beta(1 \rightarrow 4)-G l c U A \beta(1 \rightarrow 3)$ throughout a molecule that can have a molecular weight of up to $10^{6} \mathrm{Da}$. HA belongs to the glycosaminoglycan family with the particularity that it is not sulfated in comparison with other glycosaminoglycans. HA acts through a large number of proteins with the ability to bind to it, called hyaladherins [3]. The main cell surface receptor of HA is CD44, which can exist in numerous isoforms through alternative splicing of 10 variant exons in different combinations [4]. 


\section{Hyaluronate: Up to Now}

In the skin, HA provides a highly hydrated medium facilitating the cell movement that occurs in the early stages of injury, inflammation, and wound healing $[5,6]$. It may also contribute to the elastic properties of the dermis by forming a network of helicoidal structures, to epidermal differentiation, and also to lipid synthesis/secretion [7-9].

HA is a crucial molecule in the process of skin aging since levels of HA gradually decrease with age [10]. Cosmetics often propose HA as an active ingredient, but topical HA applications do not lead to an increase in HA-specific staining intensity, suggesting that the large molecule is poorly able to permeate the stratum corneum of viable human epidermis, both ex vivo and in vitro [11,12]. Another solution to correct wrinkles and folds is the use of HA injections [13]. HA fillers provide structural support for the collagen fibers. Treatment with HA injections is not permanent, and visible results last about 6 months. Several fillers received approval by the US Food and Drug Administration. HA dermal fillers are considered to be safe and effective [14$16]$. Their advantage is that they offer longer-lasting correction than collagen fillers $[17,18]$.

\section{Hyaluronate Fragments: From Now On}

In addition to its viscoelastic properties, HA may be cleaved into fragments of smaller molecular weight, called hyaluronate fragments (HAF), which are the degradation products derived from the action of hyaluronidases, $\beta$-glucuronidase, or hexosaminidase on HA. HAF have distinct physiological properties, such as stimulation of cell turnover, angiogenesis, tissue remodeling, or activation of the innate immune defense [19-21].

Many studies suggest that cell responses after HA treatment depend on the size of the fragments as well as on the cell type. Thus, HAF may exert differential regulation on the wound-healing process [22]. They also induce epithelial cell proliferation and HA synthase expression, thereby stimulating endogenous HA production [12]. However, we have demonstrated that only HAF between 50 and $400 \mathrm{kDa}$ (intermediate size, HAFi) were able to induce an epidermal hyperplasia, to increase the density of the dermis and HA content through a CD44-dependent pathway [12]. In a recent study that we conducted on 10 subjects, we showed that daily topical application of HAFi for 5 days increased the HA content in the superficial dermis of the skin already injected by a noncross-linked HA (Fig. 1). Therefore, HAFi act as an epicutaneous (or topical) HA filler (Fig. 2).

\section{Therapeutic Applications of HAF}

\section{Dermatoporosis}

The term "dermatoporosis" was proposed to cover the different manifestations and implications of the chronic cutaneous insufficiency/fragility syndrome in the elderly and to facilitate the understanding that, as osteoporosis, dermatoporosis should be treated to prevent complications $[23,24]$. We have shown that dermatoporosis is due to the dysfunction of hyalurosome, which is a putative multimeric macromolecule complex composed of molecules involved in HA metabolism and cell signaling in keratinocytes, such as CD44, heparinbinding epidermal growth factor (HB-EGF), and its receptor erbB1 [25]. Epidermal Lrig1+ progenitor cells, Wnt/ $\beta$-catenin pathway, calcium signaling, and $\mathrm{p} 16^{\text {Ink4a }}$ pathway also play a role in the pathogenesis of dermatoporosis [24, 26, 27]. HAFi might constitute a target molecule for the prevention of cutaneous aging and the reversal of the skin atrophy observed in dermatoporotic patients [12]. Inhibition of a putative hyalurosome complex in keratino- 
Fig. 1. HAFi increase the HA in the superficial dermis of HA-injected human skin. Colloidal iron (a, b) and $\operatorname{HABP}(\mathbf{c}, \mathbf{d})$ staining of human skin injected with a noncross-linked HA (a-d) and subjected to a daily topical application of HAFi for 5 days $(\mathbf{b}, \mathbf{d})$. Note the diffuse dermal staining of HA in blue $(\mathbf{a}, \mathbf{b})$ and in brown $(\mathbf{c}, \mathbf{d})$ and the accumulation of HA in the superficial dermis just beneath the dermal-epidermal junction in HAFi-applied skin (b, d, arrowheads). HABP, hyaluronan binding protein.
Kaya et al.: Induction of Hyalurosome by Topical Hyaluronate Fragments Results in Superficial Filling of the Skin Complementary to Hyaluronate Filler Injections
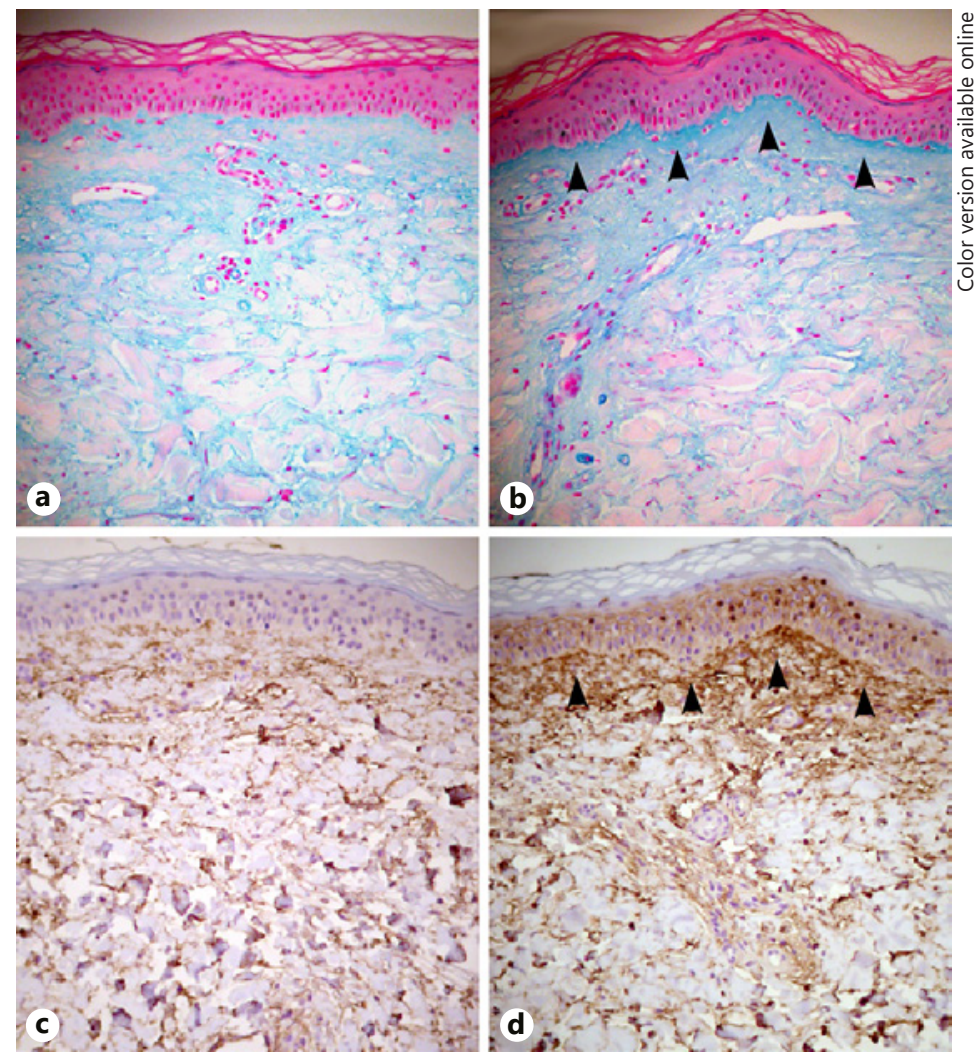

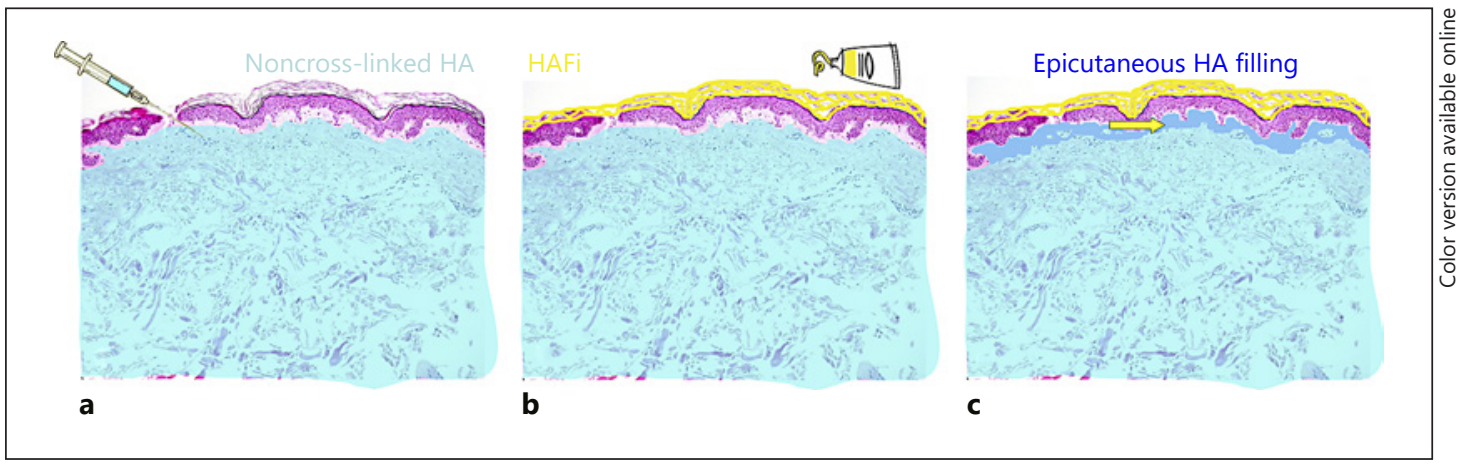

Fig. 2. Schematic representation of the epicutaneous filling effect of HAFi. Noncross-linked HA shows its filling effect (light blue color) in the mid- and deep dermis (a). Topically applied HAFi (b) act as an epicutaneous filler by filling the superficial dermis with HA (dark blue color, yellow arrow in c).

cytes seems to be the molecular mechanism for corticosteroid-induced dermatoporosis [28]. We have recently demonstrated that HAFi induced hyalurosome complex resulting in EGFR activation via CD44v3 $[12,28]$. The resulting effect was the stimulation of cell proliferation and epidermal hyperplasia in dermatoporotic patients [12]. Topical HAFi induced the expression of hyalurosome components in dermatoporotic skin [29].

\section{HAFi in Association with Retinoids}

Retinoids, including retinaldehyde (RAL), are well known in the treatment of skin aging [30]. RAL induces keratinocyte proliferation through a CD44-dependent mechanism and 
Kaya et al.: Induction of Hyalurosome by Topical Hyaluronate Fragments Results in Superficial Filling of the Skin Complementary to Hyaluronate Filler Injections

Table 1. The different types of biological activity of hyaluronic acid

\begin{tabular}{lllll}
\hline Administration & Type of HA & Method of action & Type & Effect \\
\hline Intradermal & Native molecule & Increases dermal mass & 1 & $\begin{array}{l}\text { Filling and viscoelastic effects in the } \\
\text { dermis }\end{array}$ \\
\hline Topical (epicutaneous) & Fragments (HAFi) & $\begin{array}{l}\text { Induces HA production in the } \\
\text { epidermis and upper dermis }\end{array}$ & 2 & $\begin{array}{l}\text { Filling and viscoelastic effects in the } \\
\text { epidermis and upper dermis }\end{array}$ \\
\hline Topical (epicutaneous) & Native molecule & Traps water & 3 & Water retention \\
\hline
\end{tabular}

upregulates the HA synthesizing enzymes in mouse skin [25, 31]. We have recently demonstrated that topical applications of RAL and/or HAFi also induce CD44 expression in the epidermis, as well as increasing the dermal and epidermal HA content. These effects are more significant than treatment with RAL or HAFi alone, suggesting that these 2 components have a synergistic action $[25,29]$.

A recent clinical study showed that applications of a topical preparation containing a combination of RAL and HAFi optimized the results obtained with injectable HA for both parameters measured, skin texture and dermal thickness [32]. These results suggest that topical HAFi and HA fillers have complementary biological activities.

\section{Proposal of a New Classification of the Biological Activities of HA}

A new classification of the biological activities of hyaluronic acid may be proposed based on size and method of administration (Table 1). The 2 biological activities of HA involving (1) viscoelastic filling (type 1) and (2) its role as an intercellular messenger, HAFi (type 2), could be used with a view to prevent and reverse cutaneous aging and dermatoporosis. It follows from this reasoning that HA skin treatment should combine type 1 and type 2 activities, with a variable type 1 /type 2 ratio.

Type 3 activity corresponds to HA's function in water retention and its ability to combine with water to form a complex in the intercellular environment and in connective tissue in particular. In this way, the space it occupies enables the retention of smaller molecules, such as growth factors or electrolytes.

\section{Disclosure Statement}

The authors declare no conflicts of interest.

\section{References}

1 Laurent TC, Fraser JR. Hyaluronan. FASEB J. 1992 Apr;6(7):2397-404.

2 Prehm P. Hyaluronate is synthesized at plasma membranes. Biochem J. 1984 Jun;220(2):597-600.

3 Viola M, Vigetti D, Karousou E, D’Angelo ML, Caon I, Moretto P, et al. Biology and biotechnology of hyaluronan. Glycoconj J. 2015 May;32(3-4):93-103.

4 Bajorath J. Molecular organization, structural features, and ligand binding characteristics of CD44, a highly variable cell surface glycoprotein with multiple functions. Proteins. 2000 May;39(2):103-11.

5 Keen MA. Hyaluronic Acid in Dermatology. Skinmed. 2017 Dec;15(6):441-8. 
6 Chen WY, Abatangelo G. Functions of hyaluronan in wound repair. Wound Repair Regen. 1999 Mar-Apr;7(2): 79-89.

7 Tammi R, Tammi M. Correlations between hyaluronan and epidermal proliferation as studied by [3H]glucosamine and $[3 \mathrm{H}]$ thymidine incorporations and staining of hyaluronan on mitotic keratinocytes. Exp Cell Res. 1991 Aug;195(2):524-7.

8 Bernstein EF, Underhill CB, Hahn PJ, Brown DB, Uitto J. Chronic sun exposure alters both the content and distribution of dermal glycosaminoglycans. Br J Dermatol. 1996 Aug;135(2):255-62.

9 Bourguignon LY, Ramez M, Gilad E, Singleton PA, Man MQ, Crumrine DA, et al. Hyaluronan-CD44 interaction stimulates keratinocyte differentiation, lamellar body formation/secretion, and permeability barrier homeostasis. J Invest Dermatol. 2006 Jun;126(6):1356-65.

10 Ghersetich I, Lotti T, Campanile G, Grappone C, Dini G. Hyaluronic acid in cutaneous intrinsic aging. Int J Dermatol. 1994 Feb;33(2):119-22.

11 Laugier JP, Shuster S, Rosdy M, Csóka AB, Stern R, Maibach HI. Topical hyaluronidase decreases hyaluronic acid and CD44 in human skin and in reconstituted human epidermis: evidence that hyaluronidase can permeate the stratum corneum. Br J Dermatol. 2000 Feb;142(2):226-33.

12 Kaya G, Tran C, Sorg O, Hotz R, Grand D, Carraux P, et al. Hyaluronate fragments reverse skin atrophy by a CD44-dependent mechanism. PLoS Med. 2006 Dec;3(12):e493.

13 Tezel A, Fredrickson GH. The science of hyaluronic acid dermal fillers. J Cosmet Laser Ther. 2008 Mar;10(1): $35-42$.

14 Bukhari SNA, Roswandi NL, Waqas M, Habib H, Hussain F, Khan S, et al. Hyaluronic acid, a promising skin rejuvenating biomedicine: A review of recent updates and pre-clinical and clinical investigations on cosmetic and nutricosmetic effects. Int J Biol Macromol. 2018 Dec;120(Pt B):1682-1695.

15 Fallacara A, Manfredini S, Durini E, Vertuani S. Hyaluronic Acid Fillers in Soft Tissue Regeneration. Facial Plast Surg. 2017 Feb;33(1):87-96.

16 Brandt FS, Cazzaniga A. Hyaluronic acid gel fillers in the management of facial aging. Clin Interv Aging. 2008; 3(1):153-9.

17 Belmontesi M, De Angelis F, Di Gregorio C, Iozzo I, Romagnoli M, Salti G, et al. Injectable Non-Animal Stabilized Hyaluronic Acid as a Skin Quality Booster: An Expert Panel Consensus. J Drugs Dermatol. 2018 Jan;17(1):83-8.

18 Baumann LS, Shamban AT, Lupo MP, Monheit GD, Thomas JA, Murphy DK, et al.; JUVEDERM vs. ZYPLAST Nasolabial Fold Study Group. Comparison of smooth-gel hyaluronic acid dermal fillers with cross-linked bovine collagen: a multicenter, double-masked, randomized, within-subject study. Dermatol Surg. 2007 Dec;33 Suppl 2:S128-35.

19 Stern R, Asari AA, Sugahara KN. Hyaluronan fragments: an information-rich system. Eur J Cell Biol. 2006 Aug; 85(8):699-715.

20 West DC, Hampson IN, Arnold F, Kumar S. Angiogenesis induced by degradation products of hyaluronic acid. Science. 1985 Jun;228(4705):1324-6.

21 Gariboldi S, Palazzo M, Zanobbio L, Selleri S, Sommariva M, Sfondrini L, et al. Low molecular weight hyaluronic acid increases the self-defense of skin epithelium by induction of beta-defensin 2 via TLR2 and TLR4. Immunol. 2008 Aug;181(3):2103-10.

22 David-Raoudi M, Tranchepain F, Deschrevel B, Vincent JC, Bogdanowicz P, Boumediene K, et al. Differential effects of hyaluronan and its fragments on fibroblasts: relation to wound healing. Wound Repair Regen. 2008 Mar-Apr;16(2):274-87.

23 Kaya G, Saurat JH. Dermatoporosis: a chronic cutaneous insufficiency/fragility syndrome. Clinicopathological features, mechanisms, prevention and potential treatments. Dermatology. 2007;215(4):284-94.

24 Kaya G, Kaya A, Sorg O, Saurat JH. Dermatoporosis: a further step to recognition. J Eur Acad Dermatol Venereol. 2018 Feb;32(2):189-91.

25 Barnes L, Tran C, Sorg O, Hotz R, Grand D, Carraux P, et al. Synergistic effect of hyaluronate fragments in retinaldehyde-induced skin hyperplasia which is a Cd44-dependent phenomenon. PLoS One. 2010 Dec; 5(12):e14372.

26 Barnes L, Saurat JH, Kaya G. Senescent Atrophic Epidermis Retains Lrig1+ Stem Cells and Loses Wnt Signaling, a Phenotype Shared with CD44KO Mice. PLoS One. 2017 Jan;12(1):e0169452.

27 Darbellay B, Barnes L, Boehncke WH, Saurat JH, Kaya G. Reversal of murine epidermal atrophy by topical modulation of calcium signaling. J Invest Dermatol. 2014 Jun;134(6):1599-608.

28 Barnes L, Ino F, Jaunin F, Saurat JH, Kaya G. Inhibition of putative hyalurosome platform in keratinocytes as a mechanism for corticosteroid-induced epidermal atrophy. J Invest Dermatol. 2013 Apr;133(4):1017-26.

29 Nikolic DS, Ziori C, Kostaki M, Fontao L, Saurat JH, Kaya G. Hyalurosome gene regulation and dose-dependent restoration of skin atrophy by retinaldehyde and defined-size hyaluronate fragments in dermatoporosis. Dermatology. 2014;229(2):110-5.

30 Sorg O, Antille C, Kaya G, Saurat JH. Retinoids in cosmeceuticals. Dermatol Ther. 2006 Sep-Oct; 19(5):289-96.

31 Kaya G, Grand D, Hotz R, Augsburger E, Carraux P, Didierjean L, et al. Upregulation of CD44 and hyaluronate synthases by topical retinoids in mouse skin. J Invest Dermatol. 2005 Jan;124(1):284-7.

32 Rouvrais C, Cours-Darne S, Coudière S, Briant A, Degouy A, SchmittAM. Evaluation de l'efficacité de l'association topique de fragments d'acide hyaluronique et de rétinaldéhyde combinée à une injection d'acide hyaluronique dans le comblement des sillons nasogéniens. Ann Dermatol Venereol. 2007;134:7S265-66 (P310). 